\title{
Relationship between human characteristics and adoption of project management information system in non-governmental organizations' projects in Nakuru Town (Kenya)
}

\author{
Oyugi Tobias, Maina Kairu \\ Department of Education and External studies, University of Nairobi, Nairobi, Kenya
}

Email address:

koyugibft@gmail.com (T. Oyugi), mainakairu@yahoo.com (K. Maina)

To cite this article:

Oyugi Tobias, Maina Kairu. Relationship between Human Characteristics and Adoption of Project Management Information System in Non-Governmental Organizations' Projects in Nakuru Town (Kenya). International Journal of Intelligent Information Systems.

Vol. 4, No. 1, 2015, pp. 16-26. doi: 10.11648/j.ijiis.20150401.13

\begin{abstract}
The purpose of this study was to determine the relationship between human characteristics and adoption of project management information system (PMIS) in non-governmental organizations' projects in Nakuru Town. The independent variable (Human characteristics) was conceptualized into; resistance to change, project management skills, user's skills and awareness, power struggles and perfectionism. These indicators were individually related with adoption of project management information system. This study adopted both descriptive and correlational design. It was a survey and primary data was collected through structured questionnaires and interviews. Both descriptive and inferential analysis was employed in this study. The research findings were presented through tables. The research findings revealed that one's competence level in using PMIS, level of training received, willingness to adapt to using PMIS, attitude towards technology and own expectation when using PMIS are positively related with adoption of project management information system. Attitudinal change and support in using the system also appeared to hugely influence adoption of PMIS. The study underscored the analogy that before the management puts pressure on using the system, they must first adopt its usage then spiral it down to subordinates. The study recommended that mentorship and training are critical drivers to successful implementation of PMIS. Training not only should be at the initiation phase of the system but embedded as a continuous skill enhancement and as part of professional development in the organization. A part from training, employees must be motivated and involved at all stages of the implementation process.
\end{abstract}

Keywords: Human Characteristics, Project Management Information System, Non-governmental Organizations

\section{Introduction}

\subsection{Background of the Study}

Advances in information technology are affecting most segments of business, society, and governments today in every part of the world (Hundley, 2004). The changes that IT is bringing about in various aspects of life are often collectively called the "information revolution (Hundley, 2004)." The current project manager must bring on board suitable technological tools and integrate such with the project practices.

PMIS as a part of IS refers to the tools and techniques used to gather, integrate, and disseminate the outputs of project management processes. It is used to support all aspects of the project from initiation through closing, and can include both manual and automated systems (PMI, 2008). In line with information systems experts and already existing body of knowledge and in the description of MIS technology; emphasis is put explicitly on organizational/firms characteristic and individual/user behavior (Huber 1990, Orlikowski and Lacono 2000). This research thus focused specifically on the influence of human characteristics on PMIS adoption by NGO's. To this end considerations were based on traditional PMIS studies and in particular the concept of task/technology fit as developed by Goodhue and Thompson (1995) and Zigurs and Buckland (1998).

To develop the theory further, a review of different 
organizational tasks and typical MIS support was sought, and then focus on PMIS. Putting the theory into perspective and appreciating that it cannot be used entirely in supporting MIS adoption on its own, other proposed theories were as well evaluated and factors that can support positive PMIS adoption unpacked by further research in redefining a framework for TTF's project successful..

Drawing from the Project management Maturity Model (PMMM); organizations vary on their maturity hierarchy based on their specific goals, strategies, resource capabilities, scope and needs. TTF theory by its design assumes that the technology will take care of the diverse needs of the system but does not capture in its three tenets the social characteristics of the ever changing existing project team. At whichever level of the PMMM i.e. awareness, understanding or adoption social aspects are very key in full use and integration of the system into the organizational processes. As aforementioned, the gap in operation of the TTF model to successful use of a PMIS informs this study by acknowledging that system implementation must be a dynamic exercise that takes into cognizance an integrated approach to the myriad of IS theories. Further, the information required by management for their decision making are more summarized and requires off-line interpretation which cannot be generated by the PMIS yet this dimension has been left out in the TTF theoretical framework. Appreciating dynamism in theories, the study further redefines TTF to capture management decision making in the context of the social dimension.

\subsection{Research Objectives}

This study was guided by two objectives:

- To establish the influence of resistance to change on adoption of project management information system in non-governmental organizations' projects

- To establish the influence of project management skills on adoption of project management information system in non-governmental organizations' projects

- To establish the influence of user's skills and awareness on adoption of project management information system in non-governmental organizations' projects

- To establish the influence power struggles and perfectionism on adoption of project management information system in non-governmental organizations' projects

\subsection{Research Hypothesis}

Ho1: Resistance to change negatively influence adoption of PMIS in non-governmental organizations' projects

Ho2: Project management skills negatively influence adoption of PMIS in non-governmental organizations' projects

Ho3: User's skills and awareness negatively influence adoption of PMIS in non-governmental organizations' projects

Ho4: Power struggles and perfectionism negatively influence adoption of PMIS in non-governmental organizations' projects

\subsection{Conceptual Framework}

The design of the conceptual framework outlines the independent and dependent variables in the study. The independent variable (organizational factors) is conceptualized into operational factors and human characteristics and related with implementation of project management information system. Three intervening and four moderating variables are also captured in the framework to ensure reliability of making generalizations after data analysis.

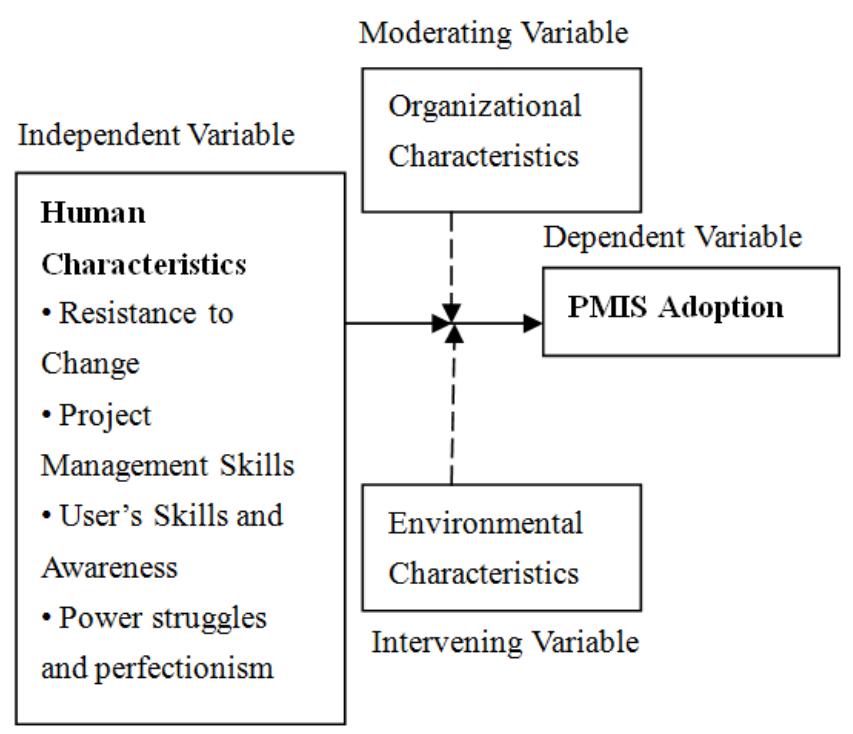

Figure 1. Conceptual Framework

\section{Literature Review}

\subsection{Human Characteristics}

These relate to the interpersonal skills of the individuals involved with the project. Burke et al (2001) suggests that human issues have the biggest impact on the process as they argue that when implementation and adoption of information systems is successful, it is because a focused attention was paid to the human issues. This prompts discussion into the following areas:

\subsubsection{Poor Project Management}

Out of the many organizations that have adopted PMIS, very few have had the experience in running such systems especially on a large scale front. Most organizations will involve consulting firms in the process from design to implementation, this poses a challenge for if the senior management is not fully involved their information expectation from the system will not be in synch with what would be users will be generating. Implementation of projects thus needs very close working ties between the executive management, the middle management and the hands on workers to ensure that the right participation mix of business and IT is done and to resolve later conflicts (Turbit, 2005). 
Top management support is therefore a critical organizational factor for the success of PMIS adoption and diffusion (Omware et al., 2014).

\subsubsection{Lack of User's Skills and Awareness}

Burke et al (2001) identified poor skill sets among users as an issue. This view is supported by research by META Group (2004) that indicated that more than $75 \%$ of organizations identified lack of user awareness as a challenging factor. Furthermore, in the same study, $66 \%$ of organizations identified lack of executive awareness as having a similar effect. Martin Harvey, the director of IT user skills at e-skills UK, states that lack of user skills is "a major problem" which is supported by a recent study showing that 7.6 million employees needed improved IT skills out of the 21.5 million IT-using work forces (Murray, 2007). It is also suggested by Turbit (2005) that when upgrading from old technology, the skills of the staff need to be upgraded as well.

The upgrade will place significant demands on the team who are geared to maintain an old but stable environment; usually this effort is underestimated by most organizations. Fear of technological changes often is attributed to user's lack of confidence in articulating tasks which therefore means the challenge to be locked out in the implementation of a PMIS. In keeping in line with imminent change in organizations, a continuous professional development approach must be rooted at the organizational policy level so as to guarantee success when systems change.

\subsubsection{Resistance to Change}

This refers to the refusal by individuals to reap the benefits of a new system. Burke et al, (2001) posits that as long as what the individuals are comfortable with works for them, there is no need trying what they are jittery might not work even before trialing its' usage. A case study based on Hayward Gordon Ltd. (HGL) in 2004 revealed that one of their major human issues was that people can become lazy and copy electronic records. A study by Gupta (2000) revealed that the main hurdle faced by most companies was resistance to change. He expanded on this by explaining that resistance was due to employees being reluctant to change due to its attachment to the product. Employees play an important role as Muguire (2000) identifies that the "vast majority of IS's used by staff within the organizations". Moguire (2000) also notes that there are still too many examples of IS projects that have failed due to increasing problems of rising costs and the misuse of IS rather than acceptance and use of the system. PMIS seen by many as a good thing still has its challenges of user's resisting usage for a myriad reasons that are more personal; research thus must delve into the causes of user resistance and out wittingly expose such factors.

\subsubsection{Benign Neglect}

Ignoring the situation and refusing to stay on track or fulfill responsibilities (Burke et al, 2001) means there is lack of focus on the project which indicates that the organization is not very inclined to seeing the implementation of the IS a success. Benign neglect is mostly displayed by the users as if they are against the implementation of the PMIS. They may refuse to take part in making the system successful (Magutu,et al.2010). Benign neglect is synonymous with resistance to change but it is seen as its key component. Non participatory consultation in the implementation of systems is disastrous to organizations which therefore demand an all-inclusive approach through the entire project lifecycle if success is to be realized.

\subsubsection{Power Struggles and Perfectionism}

Synonymous with all organizations, power struggles and hierarchical perception of positions is usually a recipe for chaos. Who is responsible for what? Who owns what information? Are questions that must be addressed for the success of the smooth running of IS‘s. Power struggles and employee relations often occur leading to implementation challenges (Burke et al, 2001). Perfectionism occurs when certain users refuse to use the ISs because it is not working exactly as specified. In information systems project implementation, a huge amount of work requires the analysis and interpretation of data and input from many people. Inadequacies in such a process could have significant consequences later on in the project, causing even something dramatic as redesign and re-implementation (Burke et al, 2001). It is therefore quite prudent for the project team to work harmoniously at each stage not only to accomplish the tasks at hand but to guarantee integrity and security of the data and information that is in the system

\subsection{Project Management Information System}

Project management has historically been considered an important characteristic of successful companies; this analogy has been supported by the need for improved efficiency and effectiveness in managing projects (Wesonga et al., 2014). Several PMIS's have been developed and adopted by many organizations both in the private and public sector with a sole objective of making significant contribution to enhancing project management. Just like other IS, a successful PMIS should have individual impacts evident in user satisfaction and effective use. A successful PMIS must also have organizational impacts, that is, impacts on project success in terms of respecting budget, schedule and specifications. While projects increasingly procure PMIS, not much is known on the characteristics of these systems that contribute to adoption and project success; empirical analysis of adoption models and what constitutes a PMIS is aimed at unlocking this relationship.

Maredith and Mantel (2006) found that utilizing IT has a major impact in solving all difficulties that may appear during the project's lifecycle. This is achieved through the various applications that constitute a PMIS; in procuring a PMIS it is prudent to evaluate such functionalities and even further seek to know if value adds components such as project risk management module and knowledge management are integrated (Ahlemann, 2007). Monitoring and evaluation being very essential components of projects; their inclusion as part and parcel of the standard modules of a 
PMIS is quite fundamental.

Essentially, the task of PMIS has been described as subservient to the attainment of project goals and the implementation of project strategies; it provides project managers with essential information on the cost-time performance parameters of a project and on the interrelationship of these parameters (Raymond 1., 1987). In the IT industry today, Gartner research estimates that $75 \%$ of projects managed with PMIS support will succeed while $75 \%$ of projects without such support will fail (Light M., et.al., 2005). In light of this, research also cautions that only a small number of projects utilize all PMIS tools during the project management life cycle such as planning, scheduling, risk management, cost estimates, document management, communicating, and reporting (Herroelen,2005; Love \& Irani 2003).

\subsection{Theoretical Framework}

There are many theories used in MIS research (Wade 2009). This study is interested only in theories about PMIS technology adoption. The most used theories are Technology Acceptance Model, Theory of Planned Behavior, and Unified Theory of Acceptance to Use Technology, Task Technology Fit, Diffusion of Innovation and Expectancy Confirmation Theory. In reviewing these theories of MIS adoption, the study puts into perspective the two tenets that dictate how well MIS is acceptable and adopted by an organization i.e. the firm level and the individual level based on DOI model.

\subsubsection{Innovation Theory}

Individuals are seen as possessing different degrees of willingness to adopt technology, and thus it is generally observed that the portion of the population adopting an innovation is approximately normally distributed over time (Rogers 1995). Breaking this normal distribution into segments leads to the segregation of individuals in to the following five categories of individual innovativeness (from earliest to latest adopters): innovators, early adopters, early majority, late majority and laggards (Rogers 1995).

At the firm level (Rogers 1995), technology adoption is related to such independent variables as individual (leader) characteristics, internal organizational structural characteristics, and external characteristics of the organization. Individual characteristics describe the leader attitude towards change and internal characteristics of organizational structure include observations according to Rogers (1995) whereby: "centralization is the degree to which power and control in a system are concentrated in the hands of a relatively few individuals", "complexity is the degree to which an organization's members possess a relatively high level of knowledge and expertise"; "formalization is the degree to which an organization emphasizes its members' following rules and procedures"; "interconnectedness is the degree to which the units in a social system are linked by interpersonal networks"; organizational slack is the degree to which uncommitted resources are available to an organization", "size is the number of employees of the organization". External characteristics of an organization refer to the system openness.

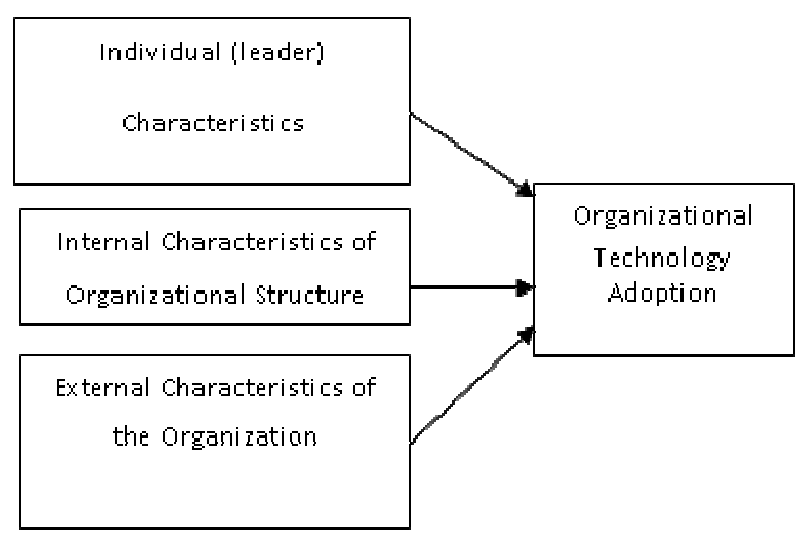

Figure 2. Innovations theory

Source: Rogers (1995).

\subsubsection{Technology Acceptance Theory}

The Technology Acceptance theory (TAT) also referred to Technology acceptance model (TAM) (Davis 1985, Davis et al. 1998) is a specific adaptation of the Theory of Reasoned Action (TRA) model (Ajzen and Fishbein 1980) to the study of IT usage. The TRA and its successor, the Theory of Planned Behavior (TPB) (Ajzen 1985), are well known, and have been widely employed in the study of specific behaviors (Ajzen and Fishbein 1980). In general, these theories (TRA, TAM) state that a behavior is determined by intention to perform the behavior. Actual behavior and intention have been found to be highly correlated (Davis 1985, Fishbein and Ajzen 1980). Intention, itself, is determined by attitude towards behavior.

Davis' research, in essence examines the external variables that determine or influence attitude towards IT use. The TAM identifies Perceived Ease of Use and Perceived Usefulness as key independent variables (Davis 1989). Perceived Ease of Use also influences Perceived Usefulness. The TAM includes the very important assumption that behavior is volitional, which is to say voluntary or at the discretion of the user. The TAM has been tested in several studies of IT use (Adams et al. 1992, Davis et al.1989, Mathieson, 1991, Straub et al. 1997).

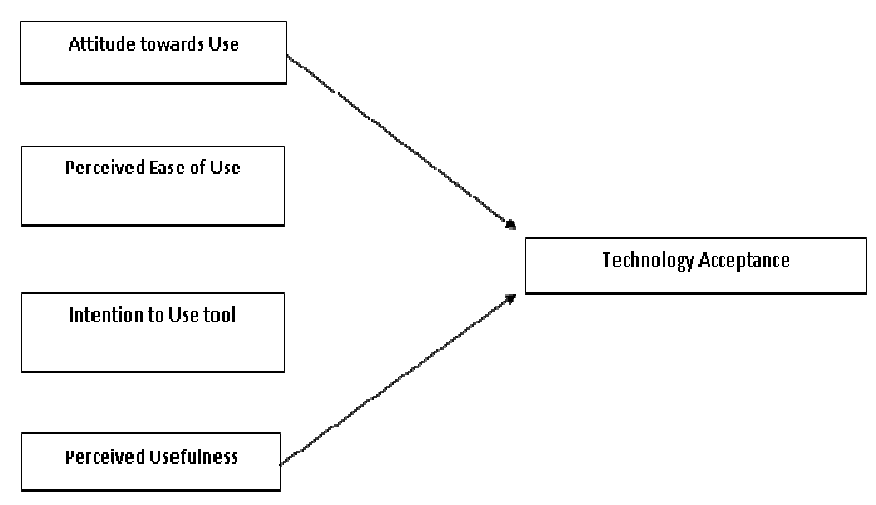

Figure 3. Technology Acceptance Framework

Source: Davis et al. (1998) 


\subsubsection{Theory of Acceptance and Use of Technology}

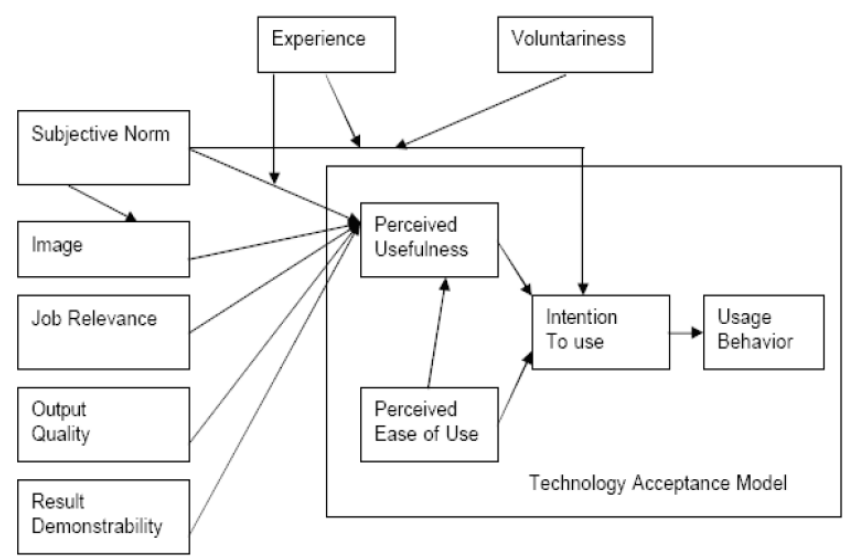

Figure 4. Theory of Acceptance and Use of Technology

Source: Venkatesh et al. (2003).

Recently, Venkatesh et al. (2003) reviewed the eight most prominent models/theories (Theory of Reasoned Action (TRA), Technology Acceptance Model (TAM), Motivational Model (MM), Theory of Planned Behavior (TPB), Combined TAM and TPB (C-TAMTPB), Model of PC Utilization (MPCU), Innovation Diffusion Theory (IDT), Social Cognitive Theory (SCT)) that predict behavioral intentions and/or usage, developed a unified model that incorporates elements of the previous eight models, and empirically validated the resulting model. This new model, known as the Unified Theory of Acceptance and Use of Technology (UTAUT) is depicted in Figure 1. Venkatesh et al. (2003) report their model explains up to seventy percent of variance in intention to use technology, outperforming previous models.

\subsubsection{Planned Behavior Theory}

Ajzen and Fishbein formulated in 1980 the theory of reasoned action (TRA). This resulted from attitude research from the Expectancy Value Models. Ajzen and Fishbein formulated the TRA after trying to estimate the discrepancy between attitude and behavior. This TRA was related to voluntary behavior. Later on behavior appeared not to be $100 \%$ voluntary and under control, this resulted in the addition of perceived behavioral control. With this addition the theory was called the theory of planned behavior $(\mathrm{TpB})$. The theory of planned behavior is a theory which predicts deliberate behavior, because behavior can be deliberative and planned.

The theory of planned behavior holds that only specific attitudes toward the behavior in question can be expected to predict that behavior. In addition to measuring attitudes toward the behavior, we also need to measure people's subjective norms - their beliefs about how people they care about will view the behavior in question. To predict someone's intentions, knowing these beliefs can be as important as knowing the person's attitudes. Finally, perceived behavioral control influences intentions. Perceived behavioral control refers to people's perceptions of their ability to perform a given behavior. These predictors lead to intention. A general rule, the more favorable the attitude and the subjective norm, and the greater the perceived control the stronger should the person's intention to perform the behavior in question.

\subsubsection{Expectation Confirmation Theory}

Expectation-confirmation theory (ECT) is widely used in the consumer behavior literature to study consumer satisfaction, post-purchase behavior, and service marketing in general (Anderson and Sullivan 1993; Dabholkar et al. 2002; Oliver 1980, 1993; Patterson et al. 1997; Tse and Wilton 1988). The predictive ability of this theory has been demonstrated over a wide range of product repurchase and service continuance contexts, including automobile repurchase (Oliver 1993), camcorder repurchase (Spreng et al. 1996), institutional repurchase of photographic products (Dabholkar et al. 2002), restaurant service (Swan and Trawick 1981), and business professional services (Patterson et al. 1997). Figure 10 illustrates key constructs and relationships in ECT. The process by which consumers reach repurchase intentions in an ECT framework is as follows (Oliver 1980).

First, consumers form an initial expectation of a specific product or service prior to purchase. Second, they accept and use that product or service. Following a period of initial consumption, they form perceptions about its performance. Third, they assess its perceived performance vis-à-vis their original expectation and determine the extent to which their expectation is confirmed (confirmation). Fourth, they form a satisfaction, or affect, based on their confirmation level and expectation on which that confirmation was based. Finally, satisfied consumers form a repurchase intention, while dissatisfied users discontinue its subsequent use.

ECT holds that consumer's intention to repurchase a product or continue service use is determined primarily by their satisfaction with prior use of that product or service (Anderson and Sullivan 1993; Oliver 1980, 1993). Satisfaction is viewed as the key to building and retaining a loyal base of long term consumer's .Investing in customer satisfaction is like taking out an insurance policy. If some temporary hardship befalls the firm, customers will be more likely to remain loyal. (Anderson and Sullivan 1993). Satisfaction was initially defined by Locke (1976) in the context of job performance as a pleasurable or positive emotional state resulting from the appraisal of one's job.

\section{Research Methodology}

\subsection{Research Design}

This study adopted a descriptive research design. It was a survey and both qualitative and quantitative approaches were employed. According to Garson (2008), survey research is suitable in the case researcher wants to establish more variables relevant to the study which can then be used to inform application or interventions in other similar contexts. 


\subsection{The Target Population}

The target population for this study was the non-governmental organizations within Nakuru town, mainly that have operations outside the town that requires remote linkage with the main offices in Nakuru for local NGO's and international headquarters for those that are international. Within these NGO's, the study focused on Project managers and the functional project coordinators in each of their project areas. Currently there are 1195 NGO' in Nakuru Town (NGO coordination board 2012) with 145 having operations outside Nakuru town and with linkages in other towns both local and international.

\subsection{Sampling Procedure}

The determination of the sample size was done using Cochran's (1977) formulas. Cochran's sample size for categorical data is:

$$
\mathrm{n}=\mathrm{t} 2 \mathrm{pq} / \mathrm{d} 2
$$

$$
(1.96) 2(.50)(.50) /(.50) 2
$$

$\mathrm{n}$ thus $=384$

Where: $\mathrm{n}=$ desired sample size

$\mathrm{t}=$ value of selected alpha level of 0.25 in each tail $=1.96$ (the alpha level of 0.5 indicates the level of risk the researcher is willing to take; the true margin of error may exceed the margin of acceptable margin of error.

$\mathrm{pq}=$ estimate of variance $=0.25$ (maximum possible proportion (.50) producing maximum possible sample size)

$\mathrm{d}=$ acceptable margin of error

Therefore for a population of 90 NGO's (270) with PMIS the required sample size is calculated as follows:

$\mathrm{nf}=\mathrm{N} /(1+\mathrm{n} /$ population $)$

$\mathrm{nf}=384 /(1+(384 / 270)$

$\mathrm{nf}=160$

The study used a sample size of 159 respondents comprising project managers and coordinators distributed across all selected 53 NGO's which mathematically fit within the $1: 2$ ratio though not 160 as above.

\subsection{Data Collection}

Structure questionnaires were used to collect primary data. The questionnaires were given to the respondents after which they were picked for analysis. To ensure the qualitative data is obtained, In-depth Interviews was used based on the duties and responsibilities of the respondents.

\subsection{Validity and Reliability Test}

Mugenda and Mugenda (2003) assets that validity has everything to do with how accurately the data obtained in the study represents the variables therein; if such data is a true reflection of the variables, then inferences based on such, data will be accurate and meaningful. It is noted also that, a non-random error which is unidirectional dissuades the research findings to a specific conclusion when instrument validity is taken for granted. In this study, existing hypothetical connotations in MIS research were used in developing the research tools; in a pre-test administration of these tools a close eye was kept on the inclination of the findings to the proposed hypotheses.

Muma et al. (2014) define reliability as the measure of the degree to which a research instrument yields consistent results or data after repeated trials. The pretest method was used to provide the researcher to refine the final questionnaire to be used in the actual study area. Also, the dummy questionnaire is essential when conducting a peer review with colleagues and the supervisor. Correlating the scores obtained from the selected NGO's should inform the researcher on the acceptable level of reliability; if the coefficient is high, the instrument will be said to yield data that has a high equivalent reliability. Another approach that was employed in checking for reliability is the use of the split-half reliability procedure where the researcher administers the entire instrument to a sample of respondents during the pilot test and calculates the total score for each randomly divided half i.e. odd and even numbered items of the questionnaire.

\subsection{Data Analysis}

In order to facilitate data analysis the filled up questionnaires were checked for completeness, consistency and clarity. The responses were coded by assigning a numerical value to each; this was to make them quantitative for ease of possible capture by the computer in SPSS for Windows Version 19 analysis. In order to clean up the data averages like mean and median as well as distributions like standard deviations were performed on the data sets in order to discover any anomalies and appropriate corrections done. Descriptive statistics such as frequencies, percentages, median and mode were used for quantitative analysis of the data.

For establishing the extent to which several NGO have adopted use of PMIS, a Pearson product correlation moment coefficient of selected variables were generated to obtain a general view of the respondents' opinions on the influence on PMIS adoption. The choice of these statistical tests was guided by the nature of the data as presented in the questionnaire which were mainly ordinal and nominal. To establish the magnitude of relationships as captured by the hypotheses, a cross tab chi-square coefficient guided the acceptance on non -acceptance of $\mathrm{p}$-values based on a statistical standard of measure at (0.05) 95\% confidence level. Finally to help predict if a given independent variable predicts a given dependent variable the study used regression analysis.

\section{Discussion}

\subsection{Years the Organization has been in Existence}

The below figure show the length of time an organization has existed. It further correlates how old the organization is 
and the current situation regarding PMIS usage.

Table 1. Years the organization has been in existence

\begin{tabular}{cll}
\hline Range of Years & Frequency & Percent \\
\hline Below 5 & 11 & 27.5 \\
Between 5 and 10 & 18 & 45.0 \\
Between 11 and 25 & 6 & 15.0 \\
$>25$ & 5 & 12.5 \\
Total & 40 & 100.0 \\
\hline
\end{tabular}

The above figures show that majority of the NGO's have existed for over 10 years (45\%) with a minority of $12.5 \%$ having existed for more than 25 years.

Comparing the length of their existence and driven by an analogy of growth and adoption of technology reveals that there is very minimal positive correlation $(\mathrm{r}(40)=0.081)$ between years of existence and usage of PMIS. These results imply that the existence of an organization and full adoption of PMIS are not in any way significantly related.

Table 2. Correlation between Years the organization has been in existence and PMIS usage

\begin{tabular}{llll}
\hline & & $\begin{array}{l}\text { Existence of } \\
\text { organization }\end{array}$ & $\begin{array}{l}\text { PMIS Use at } \\
\text { present }\end{array}$ \\
\hline \multirow{2}{*}{$\begin{array}{l}\text { Existence of } \\
\text { organization }\end{array}$} & Pearson Correlation & 1 & .081 \\
& $\mathrm{~N}$ & & .618 \\
& Pearson Correlation & .081 & 40 \\
PMIS Use at & Sig. (2-tailed) & .618 & 1 \\
present & $\mathrm{N}$ & 40 & \\
& & 40 & 40 \\
\hline
\end{tabular}

\subsection{Current Adoption PMIS in the NGOs}

The findings in respect to current level of usage of PMIS among the organizations are as shown in the table below.

Table 3. Current Adoption of PMIS in NGOS

\begin{tabular}{|c|c|c|c|c|c|}
\hline \multicolumn{6}{|c|}{ PMIS Use at present * Perception on PMIS Cross tabulation } \\
\hline & & & \multicolumn{2}{|c|}{ Perception on PMIS } & \multirow{2}{*}{ Total } \\
\hline & & & $\mathbf{Y}$ & $\mathbf{N}$ & \\
\hline \multirow{8}{*}{ PMIS Use at present } & \multirow{2}{*}{ Extensively used } & Count & 26 & 0 & 26 \\
\hline & & $\%$ within Perception on PMIS & $66.7 \%$ & $.0 \%$ & $65.0 \%$ \\
\hline & \multirow{2}{*}{ Quite used } & Count & 7 & 0 & 7 \\
\hline & & $\%$ within Perception on PMIS & $17.9 \%$ & $.0 \%$ & $17.5 \%$ \\
\hline & \multirow{2}{*}{ Slightly used } & Count & 1 & 1 & 2 \\
\hline & & $\%$ within Perception on PMIS & $2.6 \%$ & $100.0 \%$ & $5.0 \%$ \\
\hline & \multirow{2}{*}{ Not sure } & Count & 5 & 0 & 5 \\
\hline & & $\%$ within Perception on PMIS & $12.8 \%$ & $.0 \%$ & $12.5 \%$ \\
\hline \multirow{2}{*}{ Total } & & Count & 39 & 1 & 40 \\
\hline & & $\%$ within Perception on PMIS & $100.0 \%$ & $100.0 \%$ & $100.0 \%$ \\
\hline
\end{tabular}

\subsection{The Influence of Individual Characteristics in Ascertaining Adoption of PMIS by NGO's}

individual characteristic in ascertaining PMIS adoption and usage.

This section presents the findings related to the influence of

Table 4. Individual Characteristics Indicators

\begin{tabular}{|c|c|c|c|c|}
\hline Individual characteristic indicator & Respondent & Category & Freq. & Percent \\
\hline \multirow[t]{3}{*}{ Agreement PMIS is good } & Project managers & $\mathrm{Y}$ & 39 & 97.50 \\
\hline & & $\mathrm{N}$ & 1 & 2.50 \\
\hline & Project coordinators & $\mathrm{Y}$ & 80 & 100.00 \\
\hline \multirow[t]{2}{*}{ Training on PMIS } & Project coordinators & $\mathrm{Y}$ & 64 & 80.00 \\
\hline & & $\mathrm{N}$ & 16 & 20.00 \\
\hline \multirow[t]{4}{*}{ Willingness to use PMIS } & Project coordinators & Extremely Likely & 46 & 57.50 \\
\hline & & Quite Likely & 16 & 20.00 \\
\hline & & Not Likely & 3 & 3.80 \\
\hline & & Not Sure & 7 & 8.80 \\
\hline \multirow[t]{5}{*}{ Competency in PMIS usage } & Project coordinators & Extensively high & 44 & 55.00 \\
\hline & & Quite high & 22 & 27.50 \\
\hline & & Slightly high & 6 & 7.50 \\
\hline & & Not high & 5 & 6.30 \\
\hline & & Not sure & 3 & 3.80 \\
\hline
\end{tabular}

\subsection{Agreement that PMIS is a Good Thing in Organizations}

The results show a massive unanimity at $97.5 \%$ that PMIS is a good thing with a paltry $2.5 \%$ in the contrary. The facts as they are presented do give a perception on the management that using PMIS has far reaching advantages to the organization. Despite the disagreement at a minimum 2.5\%, personal mindset to the positive therefore gives the implication that using a PMIS is a good thing and that the increased adoption and use of a PMIS starts with the 
conviction that the benefits outweigh the failures.

\subsection{Training on PMIS Use}

Training is an essential step in adoption of PMIS use. Before the deployment of PMIS within any NGO training is presumed to have been done; in some cases, prior experience in using the PMIS enables some respondents to easily use the PMIS without any formal training. The study sought from the respondents if they had received any training on using the PMIS and the results show that $80 \%$ of users have received training on PMIS which justifies how lack of it could negatively affect adoption of PMIS. The $20 \%$ of users are of the opinion that they have not received any training which is then hypothetically tested as shown in Table 5 to show if there is reason to believe if training improves ones competence level. The results are that training does improve one's competency level and thus implying the key role it does in PMIS usage and adoption.

$\mathrm{P}<0.05$ at 0.001 thus accepting the alternative hypothesis that training indeed does enhance PMIS use competency level.

Table 5. Chi-square test on Training in PMIS use and competency level

\begin{tabular}{llll}
\hline Chi-Square Tests & & & \\
\hline & Value & df & Asymp. Sig. (2-sided) \\
\hline Pearson Chi-Square & $23.864^{\mathrm{a}}$ & 4 & .000 \\
Likelihood Ratio & 22.041 & 4 & .000 \\
Linear-by-Linear Association & 9.292 & 1 & .002 \\
N of Valid Cases & 80 & & \\
\hline
\end{tabular}

a. 7 cells $(70.0 \%)$ have expected count less than 5 . The minimum expected count is .60 .

\subsection{Competency in PMIS Usage}

The Table show five levels of competency with extensively high $55 \%$, quite high $27.5 \%$, slightly high at $7.5 \%$, not high at $6.3 \%$ and $3.8 \%$ of the respondents not sure of their competency level. System usage being mandatory in most of the NGO's under the study; indicates that for maximum adoption and usage the users must have a very high competency level. The implied understanding from these figures is that whatever approach is used to boost competency level of the users, it must be such that every user is confident in using the system. Table 7 presents a correlation between PMIS competency level and training; it is evident that there is very significant moderate positive correlation at $\mathrm{r}(80)=0.343$ indicating that indeed training to some degree does enhance ones competency level in PMIS use and by extension building ones confidence to adopting PMIS.

\subsection{Correlation between Competency in Using PMIS and Training}

Table 6 correlates competency level in PMIS usage against level of training. A Pearson correlation is used in establishing the nature of the relationship.

Table 6. Correlation between competency in Using PMIS and Training

\begin{tabular}{llll}
\hline Correlations & & $\begin{array}{l}\text { PMIS Use } \\
\text { competence }\end{array}$ & $\begin{array}{l}\text { Training on } \\
\text { PMIS use }\end{array}$ \\
\hline \multirow{2}{*}{ PMIS Use } & Pearson Correlation & 1 & $.343^{* *}$ \\
competence & Sig. (2-tailed) & & .002 \\
& N & 80 & 80 \\
Training on & Pearson Correlation & $.343^{* *}$ & 1 \\
PMIS use & Sig. (2-tailed) & .002 & \\
& N & 80 & 80 \\
\hline
\end{tabular}

**. Correlation is significant at the 0.01 level (2-tailed).

\subsection{Willingness to Use PMIS Now and in the Future}

The results show $57.5 \%$ extremely likely to use PMIS in future, $20 \%$ quite likely, $10 \%$ slightly likely 3.8 not likely and 8.8 not sure of continued use of PMIS if it still part and parcel of an organizations systems. The implied argument here was that there are certain hiccups that are likely to influence someone's continued usage of the system in the future, as presented above a huge number has a positive mindset and attitude to continued usage meaning there is willingness to patiently accommodate challenges that the system portends and that despite such challenges the belief of PMIS being a good thing cannot be whisked away.

\subsection{The Influence of Management Type and PMIS Expectations by Project Managers in Ascertaining Adoption of PMIS by NGO's}

This section presents the findings related to the influence of management type and PMIS expectations by project managers ascertaining adoption of PMIS by NGO's.

Table 7. Management characteristic indicators

\begin{tabular}{|c|c|c|c|c|}
\hline Management characteristic indicator & Respondent & Category & Frequency & Percent \\
\hline \multirow[t]{2}{*}{ Pressure on PMIS usage } & Project manager & $\mathrm{Y}$ & 52 & 65.0 \\
\hline & & $\mathrm{N}$ & 28 & 35.0 \\
\hline \multirow[t]{2}{*}{ Attitude of towards PMIS usage } & Project coordinator & $\mathrm{Y}$ & 39 & 97.5 \\
\hline & & $\mathrm{N}$ & 1 & 2.5 \\
\hline Expectation on PMIS usage & Project coordinator & Mandatory & 75 & 93.8 \\
\hline \multirow[t]{4}{*}{ Reasons for pressure in PMIS use } & Project coordinator & Skill level & 28 & 35.0 \\
\hline & & Too much work & 22 & 27.5 \\
\hline & & Attitude & 24 & 30.0 \\
\hline & & Others & 6 & 7.5 \\
\hline
\end{tabular}




\section{Conclusions and Recommendations}

The Human factors which in an organization constitutes both the management and the functional unit(s) personal attributes, skills and attitudes affects greatly PMIS adoption. Burke et al (2001) suggests that human issues have the biggest impact on the process as they argue that when implementation and adoption of information systems is successful, it is because a focused attention was paid to the human issues. This study thus concurs with current literature on the effect of human factors in influencing adoption, it however goes deep into not just establishing why their characteristic nature influences adoption but further seeks to obtain from the respondents own conviction as to what works best in their interest.

Management being the drivers of implementation in any organization was found to play not only a leadership role in PMIS usage but also was meant to inspire and instill a love for usage of the system. The study sought to find out what level in an organization the usage of the PMIS was at its high and it did indicate a fair balance at all levels. This therefore underscored the analogy that before the management puts pressure on using the system, they must first adopt its usage then spiral it down to subordinates.

Increased knowledge on ICT systems and the latest of technology was realized as a key enabler in bringing on board systems that are robust and those that are expansible into the future. Organizations planning to fully embrace PMIS must thus be in the fore front in keeping in touch with the latest in the market not only to cut a niche in their service delivery but to make informed choices that are cost effective and acceptable seamlessly across other organizations of interest.

\section{References}

[1] Ackerman, M. S. (2000). The intellectual challenge of CSCW; The gap between social requirements and technical feasibility. Human-Computer Interaction, 15 (2),179-203.

[2] Adams, D. A., Nelson, R. R. \& Todd, P. A. (1992). Perceived usefulness, ease of use, and usage of information technology: A replication. MIS Quarterly. 16(2), 227-248.

[3] Ahlemann F. (2008), Project management Software Systems Requirements, Selection Processes and Products, 5th edition. Wurzburg: BARC.

[4] Ajzen, I. (1985). From intentions to actions: A theory of planned behavior. In J. Kuhl \& J. Beckman (Eds.), Action-control: From cognition to behavior (pp. 11-39). Heidelberg: Springer Press.

[5] Ajzen, I.; and Fishbein, M. Understanding Attitudes and Predicting Social Behavior. Englewood Cliffs, NJ: Prentice-Hall, 1980.

[6] Anderson, Eugene W. and Mary W. Sullivan (1993), “The Antecedents and Consequences of Customer Satisfaction for Firms," Marketing Science, 16 (2), 129-45.
[7] Baccarini, D 1999, 'The Logical Framework Method for Defining Project Success', Project Management Journal, vol. 30, no. 4, pp. 25-32.

[8] Bergeron, F., Raymond, L., Rivard, S. \& Gara, M. F. (1995). Determinants of EIS use: testing a behavioral model. Decision Support System, 14 (1), 131-146.

[9] Brandon, D. (2002). Issues in the globalization of electronic commerce. In V. K. Murthy \& N. Shi (Eds.), Architectural issues of Web-enabled electronic business. Hershey, PA: Idea Group Publishing.

[10] Brandon, D. (2004). Project performance measurement. In P. Morris \& J. Pinto (Eds.), The Wiley guide to managing projects. New York: Wiley.

[11] Burgelman R.A., Maidique M.A. and Wheelwright S.C. 1996. 'Strategic Management of Technology and Innovation'. Irwin. Chicago. USA. Second Edition.

[12] Burke, R. J. 2001a, 'Spence and Robbins' Measures of Workaholism Components: Test-Retest Stability', Psychological Reports, Vol. 88, no. pp. 882-888.

[13] Caldwell, R. (2004). Project Management Information System: Guidlines for Planning, Implementing, and Managing a DME Project Information System. New York: CARE Press.

[14] Cleland, D. I. (2004a). Field Guide to Project Management $\left(2^{\text {nd }}\right.$ ed.). New York: McGraw-Hill Press.

[15] Cleland, D. I. (2004b). Project Management Information System in Project Management: Strategic Design and Implementation ( $5^{\text {th }}$ ed.). New York: McGraw-Hill Press.

[16] Clements, J. P. \& Gido, J. (2006). Effective Project Management. Canada: Thomson South-Western.

[17] Cochran WG. Sampling Techniques. John Wiley \& Sons:New York, 1977. pp.74-76.

[18] Cragg, P. B. and King, M. (1993). Small-Firm Computing: Motivators and Inhibitors. MIS Quarterly, 17 (1): 47-60.

[19] Dabholkar, P. A. and Bagozzi, R. (2002) An Attitudinal Model of Technology-Based Self-Service: Moderating Effects of Consumer Traits and Situational Factors, Journal of the Academy of Marketing Science, 30 (3), pp. 184-201.

[20] Davis, F. D. (1989). Perceived usefulness, perceived ease of use, and user acceptance of Information technology. MIS Quarterly. 13(3), 319-339.

[21] Davis, F.D., Bagozzi, R.P. \& Warshaw, P.R. 1989, " User acceptance of computer technology: a comparison of two theoretical models.", Management Science, vol. 35, no. 8, pp. 982-1003.

[22] DeLone, W.H., and Mclean, E.R. (1992), Information Systems Success: The Quest for the Dependent Variable, Information Systems Research, 3(1), 6095.

[23] DeLone, W.H., and Mclean, E.R. (2003), The DeLone and McLean Model of Information Systems Success: A TenYear Update, Journal of Management Information Systems, 19(4), 930.

[24] Dishaw, M. T. \& Strong, D. M. (1998a). Experience as a Moderating Variable in a Task-Technology Fit Model Presented at the Fourth Americas Conference on Information Systems. Baltimore. 
[25] Dishaw, M.T. \& Strong, D. M. (1998b). Supporting Software Maintenance with Software Engineering Tools: A Computed Task-Technology Fit Analysis. Journal of Systems and Software, 44, 107-120.

[26] Fenech, T. (1998).Using Perceived Ease of Use and Perceived Usefulness to Predict Acceptance of the World Wide Web. Computer Networks and ISDN Systems, 30 (7), 629-630.

[27] Gabber, E., The Case Against User-level NetworkingProceedings of the Third Annual Workshop on System-Area Networks (SAN-3), February 2004, Madrid Spain.

[28] Garson, G. D. (2008). Multiple regression. Retrieved January 28, 2008, from http://www2.chass.ncsu.edu/garson/pa765/regress.htm

[29] GoK (2004b). Nakuru district strategic plan. Nakuru. Government of Kenya.

[30] Goodhue, D. L. \& Thompson, R. L. (1995). Task-Technology Fit and Individual Performance. MIS Quarterly, 19 (2), 213-236.

[31] Goodhue, D. L. (1995). Understanding User Evaluations of Information Systems. Management Science, 41(12), $1827-1844$.

[32] Gupta, A. (2000) Enterprise resource planning: the emerging organizational value systems, Industrial Management \& Data Systems, April, 2000, Volume 100, Issue 3, p114-118.

[33] Havelka, D., \& Rajkumar, T.M. (2006), Using the troubled project recovery framework: Problem recognition and decision to recover. eService.Journal, 5(1), 4373.

[34] Herroelen W. (2005), Project scheduling theory and practice. Prod Oper Manage, 14(4):41332.

[35] Huber, G. P. (1990) „A Theory of the Effects of Advanced Information Technologies on Organizational Design, Intelligence, and Decision Making", The Academy of Management Review 15 (1), pp. 47-71.

[36] Hundley, R., et al. (2004). The global course of the information revolution: recurring themes and regional variations. Retrieved from www.rand.org/publications/MR/ MR1680/

[37] Information Technology: Toward a Unified View. MIS Quarterly. 27(3), 425-478.

[38] Kothari, C.R.,1985, Research Methodology- Methods and Techniques, New Delhi, Wiley Eastern Limited.

[39] Kwon, T. H.; and Zmud, R. W. "Unifying the Fragmented Models of Information Systems Implementation." In J. R. Boland, and R. Hirshheim (eds.), Critical Issues in Information Systems Research, New York: John Wiley, 1987, pp. 227-251.

[40] Laudon, K., \& Laudon, J. P. (2009). Management Information Systems $\left(11^{\text {th }}\right.$ ed.). New York: Pearson press.

[41] Light M, Rosser B, Hayward S. (2005), Realizing the benefits of projects and portfolio management. Gartner, Research ID G00125673, 131.

[42] Maciaszek, L. A. (2001). Requirements analysis and system design: Developing information systems with UML. Harlow: Addison-Wesley Press.
[43] Maguire, S. (2000) Towards a "business-led" approach to Information Systems development, Information Management \& Computer Security, December, 2000, retrieved May 10th 2006, from: http://www.emeraldinsight.com.

[44] Magutu et.al (2010), "Management Through Effective Information Quality Management (IQM) in Banking Services",AJBUMA Vol.1pp.96-111.

[45] Mathieson, K. (1991). Predicting user intentions: Comparing the Technology Acceptance Model with the Theory of Planned Behavior. Information Systems Research. 2(3), 173-191.

[46] Meredith, J. R., \& Mantel, S. J. (2006). Project management: A managerial approach (6th ed.). New York: Wiley.

[47] Mgaya, R. J. (1999). Adoption and diffusion of group support systems in Tanzania. Netherlands: Delft University of Technology Press.

[48] Model with the Theory of Planned Behavior. Information Systems Research. 2(3), 173-191.

[49] Moran, C. R. (1998). Strategic information technology planning in higher education: A new roadmap to the 21 st century academy. Bolton: Anker Publishing Press.

[50] Mugenda, O. \& Mugenda. A. (2003). Research methods Quantitative and Qualitative Approaches. Nairobi acts Press.

[51] Mugonyi, D. (2003). US queries new computer deal. General format. $\quad$ Retrieved from http://www.nationaudio.com/News/DailyNation/03092003/Ne ws/News $81 . h t m l$

[52] Muma, B. O., Nyaoga, B. R., Matwere, B. R. and Nyambega, E. K. (2014). Green Supply Chain Management and Environmental Performance among Tea Processing Firms in Kericho County, Kenya. International Journal of Economics, Finance and Management Science 2(5) 270-276

[53] Muma, B. O., Nyaoga, R. B., Matwere, R. B. and Onyango J. O. (2014). Green Supply Chain Management and Economic Performance: A Review of Tea Processing Firms in Kericho and Bomet Counties, Kenya. International Journal of Science and Research, 3 (11), 2319-7064

[54] Ndou, V. (2004). E-Government for developing countries: Opportunities and challenges. General format. Retrieved from http://www.is.cityu.edu.hk/research/ejisdc/vol18/v18r1.pdf edn.

[55] Odedra, M. (1993). Information technology policies and applications in the commonwealth countries. London: Commonwealth secretariat.

[56] Oliver, Richard L. (1980), "A Cognitive Model of the Antecedents and Consequences of Satisfaction Decisions," Journal of Marketing Research, 17 (3), 460-469.

[57] Oliver, Richard L. (1993), "Cognitive, Affective, and Attribute Bases of the Satisfaction Response," Journal of Consumer Research, 20 (3), 418-430.

[58] Oruma, B. W., Mironga, J. M. and Muma, B. O. (2014). Top Management Commitment Towards Implementation of Total Quality Management (TQM) in Construction Companies in Nakuru County-Kenya. International Journal of Economics, Finance and Management Sciences. Vol. 2, (6),332-338

[59] Peter Drucker (2004, January). What makes an effective Executive. Harvard Business review 

Information System in Non-Governmental Organizations' Projects in Nakuru Town (Kenya)

[60] Pinkerton, WJ 2003, Project management: achieving project bottom-line success, McGraw-Hill, New York.

[61] PMI (2008). A Guide to the Project Management Body of Knowledge: PMBOK Guide (3rd ed.). Pennsylvania: Project Management Institute Press.

[62] Omware Q., Nyonje, R. and Muma B. (2014). Determinants of Quality Management Practices in Kenyan Sugar Processing Industry: A Case of Chemelil Sugar Company, Kisumu County, Kenya. International Journal of Economics, Finance and Management Science.

[63] Support System Effectiveness", MIS Quarterly 22 (3), pp. 313-334.

[64] Tuman, J. J. (1988). Development and Implementation of Project Management systems. New York: Van Nostrand Reinhold Press.

[65] Turner, J. R. (1999). The Handbook of Project Based Management $2^{\text {nd }}$ ed.). Maidenhead Berkshire: McGraw-Hill.
[66] Van der Meijden, M. J., Tange, H. J., Troost, J. \& Hasman, A. (2003). Determinants of success of inpatient clinical information systems: a literature review. Med inform Associate, $10(3), 235-243$.

[67] Van Der Westhuizen, D. \& Fitzgerald, E.P. (2005). Defining and measuring project success. Proceedings of the European Conference on IS Management, Leadership and Governance. Reading, UK.

[68] Venkatesh, V.; Morris, M. G.; Davis, G. B. \& Davis F. D. (2003). User Acceptance of Information Technology: Toward a Unified View. MIS Quarterly. 27(3), 425-478.

[69] World Bank report (2008) World poverty index (Revised), Ministry of planning and Development (GoK).

[70] Yates, J. (2000, August). Origins of project management. Knowledge Magazine.

[71] Zigurs, I., and B. K. Buckland (1998) "A Theory of Task-Technology Fit and Group Support System Effectiveness", MIS Quarterly 22 (3), pp. 313-334. 